\title{
VOIDS, BRANDS, CHARACTERS, AND HOW TO DEAL WITH LOTS MIRO ROMAN
}

MIRO ROMAN is an architect and a scholar. His main focus is at the overlap of information technologies and architectural articulations. Miro holds a Master of Advanced Studies degree in Computer Aided Architectural Design from ETH Zurich, and a PHD in Architecture from ETH Zurich (2019). Since 2004 he is collaborating with Luka Vlahović on project romanvlahovic. From 2013 to 2015 he was a part of the Future Cities Laboratory, interdisciplinary research programme of the Singapore ETH Centre for Global Environmental Sustainability (SEC). Currently he is a postdoctoral researcher at the Chair of CAAD at ETH Zürich. 
FIG I

branding, mediating, curating, measuring, communicating, coding

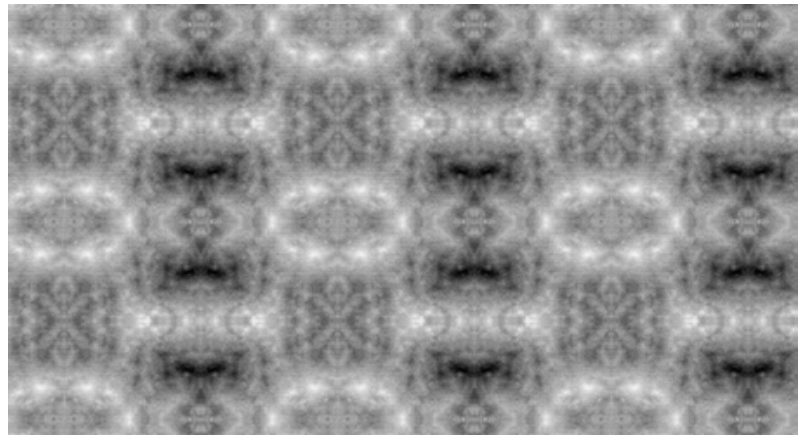

AMBIENCE

Branding, mediating, curating, measuring, communicating, coding. Information, data, lists, indexes, pixels. This story deals with a lot, with a lot of lots. By diluting common sense, it tries to play with meanings. While escaping from one understanding of nature, it participates in many traditions. Like lots do with their numerous etymological meanings. A lot can be anything from dice to straw, but also a chip of wood with a name inscribed on it used to determine someone's share. A lot is that which falls to a person by lot. A plot of land which is given by fate, God, destiny or a game of chance. With its rich meanings a lot becomes an intriguing triangle: a lottery, a group,

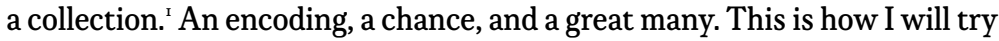
to think about big data and a big plenty. My mask is that of an architect. This text is neither scientific, nor artistic. It is architectural in always being a part of both traditions. Yet, it is architectural in another manner. Most of its elements are already around, ready to be found if one can acknowledge them. This story, like architecture, is about bringing elements, parts and things in relation. To be more precise, it is about articulating constellations with an ever-increasing number of parts: architecture, blogs, images, information, indexes... How does an architect in a world of a lot behave?

The ambience: aliens, mutants, migrants, cyborgs, avatars. Neither mortal nor immortal, neither of heaven nor of earth. Always part of streams, merging and mingling among themselves and others, with objects and collectives. Belonging to distinct natures, but still communicating. No one is pure; all are always mixtures of many kinds of creatures, of multiple worlds, of reality and fiction, of various media, of particular concepts, restless and unsystematic... Always on the move, making noise, complementing each other, enriching capacities, and producing different constellations. This is what makes it interesting, but

I Douglas Harper, 'Lot (n.)', Online Etymology Dictionary, $2017<$ https://www.etymonline. com/word/lot> [accessed 2 April 2017]. 
impossible to understand. If one looks around, there are more and more mixtures, but the more you focus, the harder you'll see. No classes, no labels, no boxes; just clouds and crystals.

Some avatars live in the cloud, on the 'Google planet'; they hang out among other avatars and aliens. Social media is their means of transportation, the manner in which they render their faces at a certain moment, in a specific locality. Yes, avatars have many faces, and they tell a lot of stories. Branding is their way of expression, Bitcoin is their currency and the way of making contracts. However we look, they influence the world. They give the real many faces. They are not realistic but a part of any specific reality; they are independent and dependent, a subject and an object, a collective. Internet, web, information, avatars - this is an immediate virtuality, with fast and direct channels to the actual and back. The virtual becomes the actual, reality and the model become one and the same. Avatars are us, modalities mix, becoming more and more complex, entangled, and less distinguishable.

This text celebrates a play of architectural avatars. It wants to articulate their faces from a lot, encode their mood as characters of weather, and write brands with their flavours. But there is no clear separation: Faces with their expressions create atmospheres, and atmosphere is a part of the weather filled with smells and odours.

\section{ARTICULATING FACES}

\section{VOID AS AN INGREDIENT}

Ours is a world of a lot, filled with creatures of varied, and ever-changing conceptions of nature. Avatars change their faces, and fashion themselves in the form they prefer. Their faces appear from a lot, disappear and reappear as brands, or blends of different characters which are in themselves encodings of lots. Brands, Characters, Lots; they can change their places, they fluctuate, while dancing around a void-a symbolic limbo between actual and virtual. Better to say: A dance, a sound - with, within and around the void. A void is being filled more and more, yet it appears empty. Its content is encrypted, and the information contained invisible. It is full and empty at the same time, depending on the cypher. These are void-elements - algebraic and complex in their appearance, inhabiting different temporalities, acting as clouds, rendered in spectrums and rainbows. In their formation, they follow the tradition of Lucretius: "[...] what we term void exists as an ingredient in things," ${ }^{2}$ while being monadic: "Now where there are no parts, neither extension, nor shape, nor divisibility is possible." ${ }^{3}$ Elements

2 Titus Lucretius Carus, On the Nature of Things, trans. by Martin Ferguson Smith (Indianapolis: Hackett Publishing Company, Inc., 2001), 967.

3 Strickland, Lloyd, Leibniz's Monadology: A New Translation and Guide, I. edition (Edinburgh: Edinburgh University Press, 2014), I4. 
without shape, a void with capacities. Void elements with an empty centre contain an empty container. They can symbolize anything, that which has no name: $\mathrm{X}$. $\mathrm{X}$ is a spectrum, a void with qualities and quantities, translatable, following many laws at the same time. It is a question of encoding and performance. Is this information?

\section{DANCING AROUND VOIDS}

\section{DANCE I - LOTS ENCODED IN CHARACTERS}

A void as an ingredient, filled elements without form, an emptiness with qualities and quantities. A void on which projections are projected to merge with other projections. These mixed projections can be imagined as characters that are encodings of a lot. Emperor in Barthes' Tokyo can be thought of as one of those characters. "The city I am talking about (Tokyo) offers this precious paradox: it does possess a centre, but this centre is empty. The entire city turns around a site both forbidden and indifferent, a residence concealed beneath foliage, protected by moats, inhabited by an emperor who is never seen, which is to say, literally, by no one knows who." All power resides in an empty centre, encoded in characters of emperor, power, tradition, institution, society, hierarchy ... Cyphers start to perform a beautiful dance, visible only if one has the key. Otherwise one is left with a generic city and an empty centre.

\section{DANCE 2 - CHARACTERS WRITING BRANDS}

On the one hand, characters encode a lot; on the other, characters write and constitute brands. Claude Lévi-Strauss in his Structural Study of Myth tells a similar story. His character is a mythical hero, a Greek god, an avatar, Oedipus. A character who is so empty that he can be loaded with new meanings repeatedly for more than two thousand years. It is an empty consistent centre which is always in motion. "On the other hand, it cannot be too strongly emphasized that all available variants should be taken into account. If Freudian comments on the Oedipus complex are a part of the Oedipus myth, then questions such as whether Cushing's version of the Zuni origin myth should be retained or discarded become irrelevant. There is no one true version of which all the others are but copies or distortions. Every version belongs to the myth." ${ }^{5}$ His avatars and characters resemble a specific alphabet or a framework of a particular thinking. It is a tradition without origin and history, a myth without sense, an ever-changing structure, a traditional structurability. I983), 30.

5 Claude Lévi-Strauss, 'The Structural Study of Myth', The Journal of American Folklore, 68.270 (1955), $428<$ https://doi.org/10.2307/536768>. 


\section{DANCE 3 - BRANDS ARTICULATED FROM LOTS}

Or to put it in different terms: Fashion as an expression of the void. Every season a new collection, consisting of different episodes, mixed genders, changing vectors. Always consistent, never explicit, articulating the same brand in different manners. Imagine a scenario:

Take a readymade concept or an artefact. Float in-between fashion and art, mix avatars and brands, Marxism and luxury. Make them dance around an empty centre. This void is articulated as a lifestyle. Cherish and emphasize contradictions. Make it public and visible, collect 'likes'. No explicit description is needed:

- Indexes: DHL, Anne Imhof, Faust, Balenciaga, Vetements, Demna Gvasalia, Ikea, Eliza Douglas, Golden Lion ...

- Package: body, performer, control, power, glass, subject, exist, dog, room, create, capitalism, consumption, image, form, hand ... ${ }^{6}$

Indexes perform a sophisticated branding, a relaxed dance of flavours symmetrical to both art and fashion shows. A lot is in the background: an ecology of videos, images, PR, stories, capital, abundance, decadence, information, lifestyles ... This beautiful fiction animates specific articulations into a play around a void.

\section{A SPECIFIC NOISE: ARCHITECTURE}

This is neither a subjective nor an objective process. It is a 'quasi-' subject, object and collective. ${ }^{7}$ A point of return to architecture. A quasi-subject needs an interest to constitute an axis and an empty centre in the entropic field. It is a generic plain of particular interest-a plain of architecture-with empty axis orthogonal to it, an avatar. Here the revolution happens. Avatars are revolving on top of the generic plain: famous architects, beautiful buildings, architectural blogs, magazines, books, manifestos, images, videos ... different styles, approaches, drawings, thinking, schools, traditions ... cities, big, small, clean, screaming, silent, efficient, sustainable, green, adventurous, smart, stupid... These are projections, new projects of the informational age. Virtual and actual at the same time. The beauty of it is that one can never explicate what it is all about. It is a position without a fixed point, a void, an attitude, both architectural and universal. There is no clear strategy; it is instead an interplay of surfing, learning, and training in a vertigo. A new ability to deal with any media as information in a world of a lot. This is what architectural brands are doing: They are navigating the clouds.

6 Anne Imhof, 'German Pavilion 2017', Faust, 2017 <http://www.deutscher-pavillon.org/>.

7 See Michel Serres, The Parasite, trans. by Lawrence R. Schehr (Baltimore: Johns Hopkins University Press, 1982). 
FIG 2

A Specific Noise:

Architecture

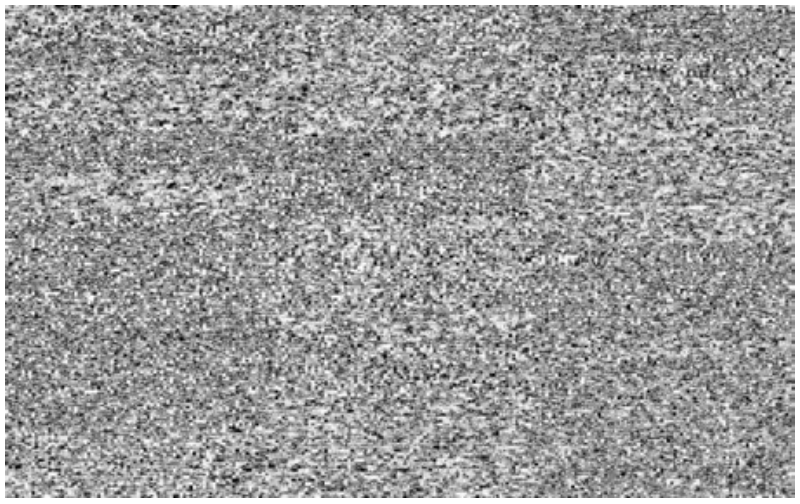

The void, the generic plane, the entropic state, all common scenarios of dissolution. From Pritzker to Google, from books to the magazine, to online magazine, to social media, finally dissolved with Google, where everything is connected to everything: A flatland. What if one inverts this story and looks at this process as parallel encapsulations that enrich each other in infinite self-referential loops? This is what the digital brings to the table: "[...] not the end of history, but an intensifying and multiplying of histories." ${ }^{8}$ Time is not flowing linearly any more: It is percolating, it's circular, it's a spiral; past, future and present are mixing; pre, post, neo, retro, futuristic, bio, techno; it's a question of taste and choice. It is digital and immediate. Time is the weather. Porn and drama mix in a new kind of public space, around a novel literacy of a quantum city. But not all is so new. Twentieth-century architectural masters were and are actively dealing with a lot. As a response, or other to early modernist tradition of Mies's "Less is more,"9 star architects reply:

Less is a bore, ${ }^{10} \mathrm{I}$ am a whore, ${ }^{\mathrm{II}}$ More and more, more is more, ${ }^{\mathrm{I2}}$ Yes is more! ${ }^{\mathrm{I3}}$

The twentieth century deals and plays with complexity, contradictions, junk, genericness, capital, brands and much more. 'More' becomes an

8 Sam Jacob, 'Faster, but Slower', Log, 29. Fall (2013), I45-52 (150).

9 Quote by Ludwig Mies van der Rohe, 1947 (borrowed from Robert Browning poem 'Andrea del Sarto' published in 1855 )

Io Robert Venturi, Complexity and Contradiction in Architecture, The Museum of Modern Art Papers on Architecture, 2nd ed. (New York: Museum of Modern Art; distributed by New York Graphic Society, 1977).

II Quote by Philip Johnson, I982.

I2 Rem Koolhaas, 'Junkspace', Obsolescence, roo. Spring (2002), 175-90.

I3 Bjarke Ingels, Yes Is More: An Archicomic on Architectural Evolution (Copenhagen: Bjarke Ingels Group, 2009). 
explication of a global condition. Architects are engaging with a lot, producing a spectrum of architectural clichés, each one with its own maxim, each in its own way. How to step out of this competition, and not add just another slogan, but still consider the spectrum? Avatars, bots, Google, cryptocurrencies, social media ... all play the game. They scan everything, relate everything to everything, make traces and trouble. They are always transmitting, not as individuals, but as multiplying and proliferating identities. The digital brings ever more to the table. It is a different world.

\section{FANTASY}

I want to play with information - store, deal, emit and receive. I want to scan ten years of online architectural publishing in one afternoon, and imagine all the different weathers and atmospheres it can produce. I want to encrypt and decrypt ... To open the crypt and move the bones of saints to another space-in other words, to translate. A crypt and a translation are spaces where information merges with materiality, where virtual and physical relate in an explicit way. It is a place where one can play with many tastes of architecture. It is a way of writing poems in a language which is not natural. Coding as literacy. ${ }^{14}$

\section{ENCODING WEATHER}

\section{PLAYING WITH CLOUDS}

Two familiar clouds, two different curations of contemporary architectural cosmos: ArchDaily ${ }^{15}$ and Dezeen. ${ }^{16}$ Both strong architectural identities-ones most liked in the network. Yet there are multiple clouds, many blogs, various consistencies, with different atmospheres and ecologies. In the digital, they mix and produce always more. The fantasy comes from mixtures. The weather changes fast. Here, focus is on the two, on their relations, behaviour, and the atmospheres they create. This, of course, is a question of preference and choice among many possible constellations.

ArchDaily and Dezeen are clouds with directionalities, without borders, but of many intensities. They bundle times, and encapsulate spaces. Indexes fill the surrounding air. It is a matter of articulation. When perceived as clouds, these curated databases gain informational abilities. With indexing, different streams appear: Texts, images, architects, drawings, times, cities ... Encoding renders specific streams to spectrums: weather, clouds, flows; not to explicate, but to open

I4 'Introduction-Coding as Literacy', in Coding as Literacy: Metalithikum IV, ed. by Vera Bühlmann, Ludger Hovestadt, and Vahid Moosavi (Basel: Birkhäuser, 2015), 12-22.

15 See https://www.archdaily.com

I6 See https://www.dezeen.com 
communication channels. The focus now goes to the stream of images: houses, sketches, floor plans, lamps, colours, homes, pixels, smells ... Current speed 30,000 images per year, per blog, and getting faster and richer. Weather forecast in architecture: storms, summers, beautiful springs, tornados ... Many atmospheres at the same time. How to play with them? Instagram, smartphones, cameras, Flickr, Pinterest, Twitter ... collect, curate, mediate, measure ... a turbulent space of flows and currents ... a characterization of stunning atmospheres ...

\section{DIGITAL ATMOSPHERE}

How does one behave in a cloud? Weather does not follow laws, not in our time at least. Its codes and manners of behaviour are not a part of the common. Digital weather is a part of an informational planet whose atmosphere is a blend of clouds, fumes, sounds and smells. It is being articulated in a quantum city ${ }^{17}$, via a new kind of literacy. Clouds and the web are a novel and different kind of space in which public, private and sacred are interwoven and fused in not-so-obvious mixtures. It is a digital agora with extraordinary atmospheres. This climate is not only reserved for big clouds like Google, Facebook, Amazon. There are many clouds and different weathers. Anyone is welcome. What if one starts playing with the atmospheres?

Scan everything, take snapshots. As an avatar in a cloud, one behaves like a search engine. Yes, it's possible, and very palpable. And suddenly one is dealing with hundreds of thousands of informational objects, without being afraid of them. One possible way to explore this is to dive right into it; personal filtering, searching, crawling, articulating. Use machine learning. Write a poem, or code a couple of them. Make sense of what the weather is like. Compose your own cloud by playing with data - play with information. Forecast a weather forecast; take snapshots, and browse the public form of online publishing; take a walk in the cloud. The first steps, the first poem. It is not too complicated: One only needs to write a crawler, a bot, a small program and collect. Here is a poem that collects all the images from ArchDaily. Ten lines for ten years. A powerful poem: 


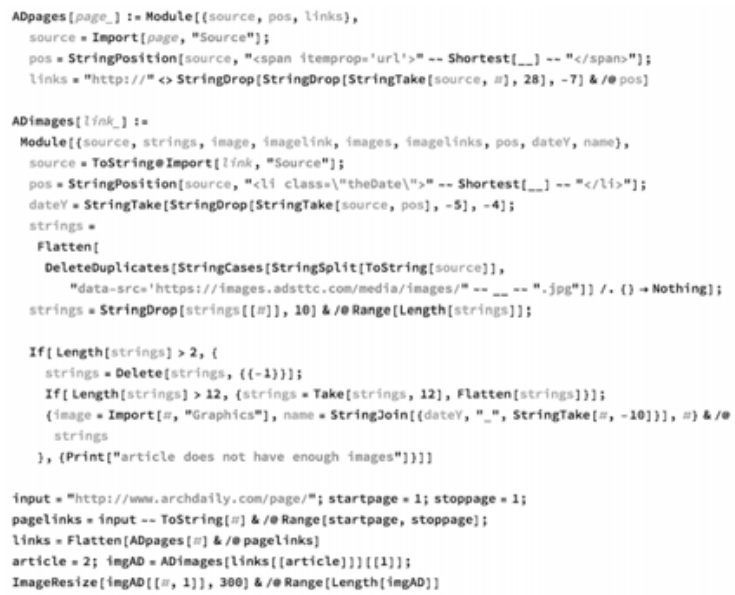

One can simply scan the cloud. This poem is able to take ro years of publishing from ArchDaily in one evening. Another poem, another online magazine, another topic, a different search. In this case it is Dezeen. Together these two online clouds provide a noisy nebula of half a million images. One is participating in a new weather. But how to look at this huge cloud? How to see half a million images and get a feel for them?

\section{ENCRYPTING FICTIONS}

Clouds are playing an informational play: ArchDaily and Dezeen acquire new identities and atmospheres - many of them. They are translated into numbers, and informationally encoded. These clouds become vectors of various directions and distinct moods. They participate in many weathers. They are curated, mediated, and measured in many manners. But how to measure a cloud? What is the unit of Dezeen? One needs to articulate the instrument and the unit. This is not a universal measuring device with a basic unit; the instrument is not scientific. It should be something different, closer to a musical instrument. Every setup produces another atmosphere. It is a subjective meter of matter in a certain manner. This does not mean one should leave and forget the seven unifying units. This is yet another way of how to think of measure. It complements the first one. Matter and meaning, nature and culture, what and how, are being co-constituted. Barad suggests: "Measurements are world-making: matter and meaning do not preexist, but rather are co-constituted via measurement intra-actions." ${ }^{18}$

I 8 Karen Barad, 'What Is the Measure of Nothingness? Infinity, Virtuality, Justice = Was Ist Das Maß Des Nichts?: Unendlichkeit, Virtualität', Gerechtigkeit, Ioo Notes - Ioo Thoughts / Ioo Notizen - Ioo Gedanken, 99 (Ostfildern: Hatje Cantz, 2012), 6. 
Yes, measurements are world-making, but the world makes the measurement as well. Basic units are in harmony, derived from the base and later from each other, but what the base is is not unambiguous any more. Clouds celebrate these contradictions, without having an explicit a priori base unit. It is a different perspective. What if it is not about measuring but about encrypting and decrypting? What if it is about making profiles of weather and mixing of clouds? Then this is another game. One is not seeking for specific properties and measuring them, but trying to develop a communication channel through which one can articulate profiles of different encodings. Electricity performs this all the time-it is energy, it is matter and it is information, a wave and a particle, depending on how one wants to have it. Different co-constitutions in their contradiction are enriching the space of possibilities. Paradoxes dope fantasy. There is no unit of image, yet images are profiling blogs from many perspectives simultaneously. This is a search for the most general and abstract ingredients in a given situation. An image becomes a constitutive part of a letter of an alphabet that articulates a blog, a void element. One is encoding frequencies to look at the clouds. These are frequencies of whatever our probes can reach. They depend on the mood of the moment. A spectrality of imageness:

- colours (most frequent RGB values)

$\{\{0.8 \mathrm{Ig} 608,0.82745 \mathrm{I}, 0.764706\},\{0.82745 \mathrm{I}, 0.835294$,

$0.768627\},\{0.854902,0.854902,0.772549\},\{0.886275$,

0.87843 I, 0.788235$\} \ldots\}$,

- edges (frequency of edges in an image)

\{o., 0.00494277, 0.000260146, o., 0., 0.201093, 0.153226,

o., $0.0293965,0.182622,0.248959,0.0176899,0.213059$,

$0.203434,0.187825 \ldots\}$,

- waves (a transformation of an image to frequency domain encoding it into sine and cosine components)

$\left\{38.4397+6.54782^{*}{ }_{10}^{\wedge}-\mathrm{I} 7 \mathrm{i},-0.0350414+3.12362 \mathrm{i}, \mathrm{I} .34676\right.$

+ I.04524i, $0.703196-0.90463 i,-0.0595718-0.736424 i$,

$-0.25928 \mathrm{I}-0.236514 \mathrm{i} \ldots\}$.

- image recognition, ratings ...

This is open. Encodings don't have a fixed form - they are code dependent. There are infinite ways of how one can encode an image. Code is beyond subjective and objective. It is a literacy. Each encoding opens a different spectrum of possible decodings. These encryptions don't define what an image is, but provide a ground for specific context and its articulations. The measurement becomes a part of the encoding process. It becomes a cypher open to many articulations. This opens a communication channel - cryptography, measurement, and communication are interwoven in a delicate way. One image, one vector, a mist. Many images, a matrix, a cloud. Clouds of images constitute a weather of a blog. 
Weathers mix and produce new weathers, virtual mutants, their families and offspring. The roots are infinite and fluid. The medium is not fixed. Encryption and indexing define the resolution. Images, texts, sounds, ratings ... Here is one. The informational encoding of Dezeen. Each row is the encoding of a different image, each column is a spectral view to a specific index (e.g., Pixel):

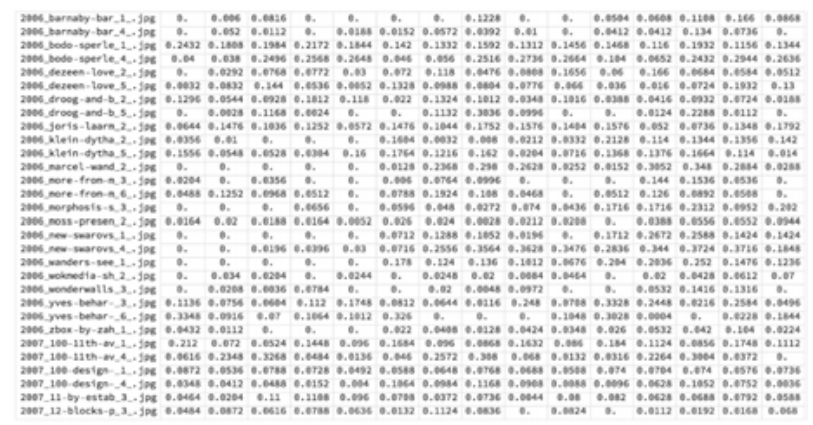

FIG 4

Informational

Encoding of Dezeen

The cloud is different now. More familiar, but less intuitive. One is suddenly playing with millions of images. Just another poem.

\section{WEATHER IN ARCHITECTURE}

The weather is changing. ArchDaily and Dezeen are the clouds. Their atmospheres and stories, mixtures and distillations, are both a matter of information, instrument and the player. Various moods come from the same cloud. They change like the weather. The way I look and what I am looking at constitutes my articulation. Jumping between contextualities constitutes an indexical cloud. Elements start to remember. A generic, informational materiality of data is articulated in an infinity of ways, never as good or bad, always in changing spectrums of many consistencies and beauties. Sophistication and branding become a part of this spectral constitution.

Here they are. Beautiful artificial articulations composed out of millions of images. Governed by poems, images gather. A specific poem, an algorithm: A Self-Organizing Map. ${ }^{19}$ Similar images group together. Similar images like each other. Similar according to my encoding. That is all: informational materiality of images and many encodings. Now decrypt, decode, decipher, and render:

I9 Teuvo Kohonen, 'Self-Organized Formation of Topologically Correct Feature Maps', Biological Cybernetics, 43.I (I982), 59-69 <https://doi.org/I0.1007/BFoo337288>. 
Weather in architecture, an architectural mutant of ArchDaily and Dezeen, an artistic cloud, ten years of architecture, an impression, a face, a rendering, different resolutions, many consistencies, various temporalities. A mixed matter of rendering, articulation, and data;

\author{
\#WeatherInArchitecture \\ \#TimeInArchitecture \\ \#TimeIsTheWeather
}

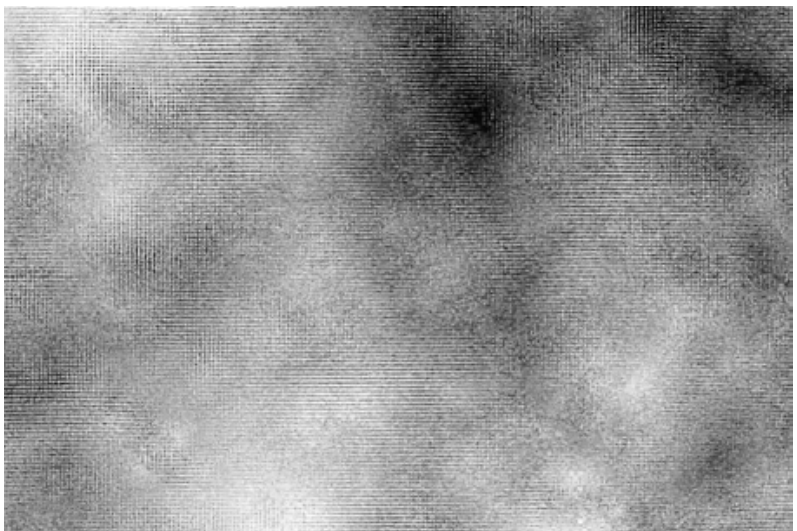

Another weather, a different interest, various renderings:

Split the mutant ${ }^{20}$, mix in many directions, split times, bundle them back, render each character individually ${ }^{21}$, by year ${ }^{22}$, check the entropy. Scan fast: What kind of photographs do they use; what kind of composition do they make, colours, objects, energy, flavours, moods, entropy ...? What is in fashion today, or ten years ago ${ }^{23}$ Just by writing short poems. Working with millions.

\title{
WRITING BLENDS
}

\section{QUEST FOR FLAVOURS}

Images, photographs, distinct compositions, beautiful colours, objects, peculiar tastes ... odours of the weather. Can this be a way to search for flavours, to articulate aromas, to compose spectrums and menus? An instrument is needed. Maybe the strings of this instrument are expressions of personal blends, informational masks, and avatars. While See http://romanvlahovic.com/img/dezeen/royearsOfDezeen.html

See http://romanvlahovic.com/bigpictures/de_yearlyPostcards_20oo.gif

See http://romanvlahovic.com/bigpictures/ad_yearlyPostcards_20oo.gif 
playing, sounds and harmonies mix into a weather composed of many flavours and distinct bouquets. Each tasting is a peculiar sensation: Never the same flavour, but an ever-changing notion of taste. Every time, its development is tuned in a slightly different fashion. The flavours, more abundant than before, concentrate into a new harmony, a blend. It is an art of combining elements, a search for constellations of concepts, consistencies and aromas inside an architectural mutant without having a clear notion of what those elements are. A question of taste: very personal, but consistent. Consistency is in the spectrum. Let's taste a few encodings. The today's menu features:

The textured objects, light in weight, like stones that fly: These are the molecules in which every element is celebrated-I have some sympathy for that-it's like a good whisky, blended, a beautiful intoxication:

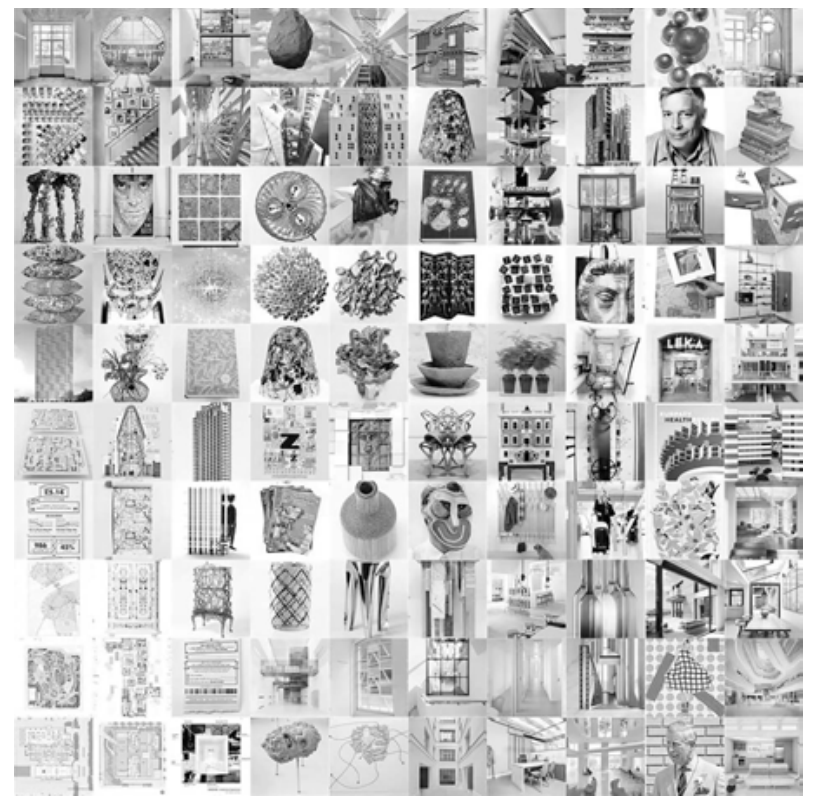

FIG 6

Flavour I

Textured Objects

Quite inverse to lonely solids heavily placed in the white abstract space. Explicit and strong in their taste. A yes or no situation. I don't like it: It is like Schweppes-works only in cocktails. But on the other hand, I like cocktails: 
FIG 7

Flavour 2

Lonely Solids

FIG 8

Flavour 3

New Chic

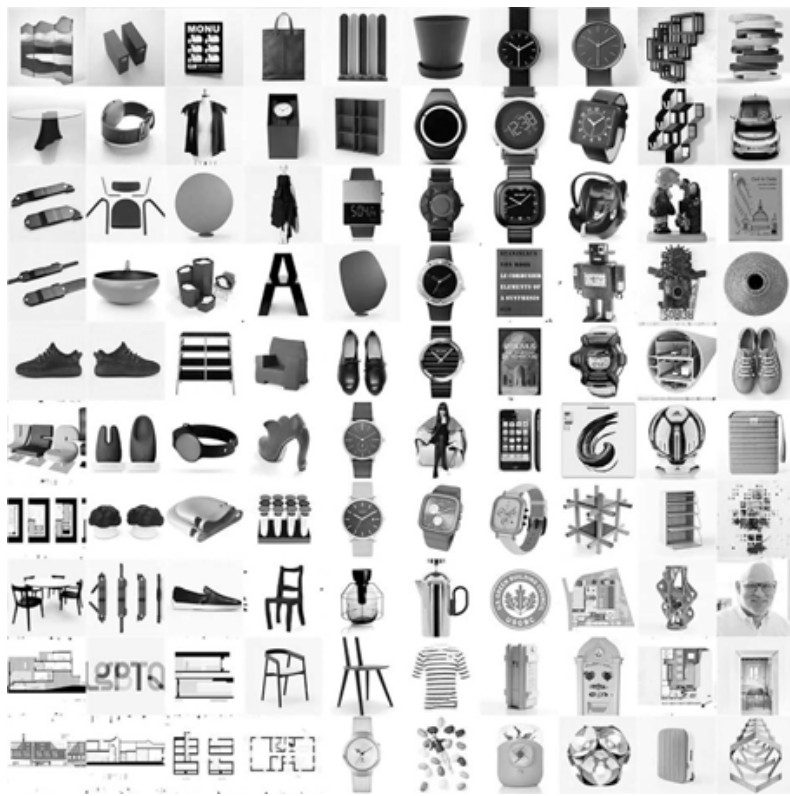

Or the new chic look - soft shadows, always interior, the floor and ceiling are merging to celebrate a specific materiality of an object-an unknown delicacy-fast as fashion:

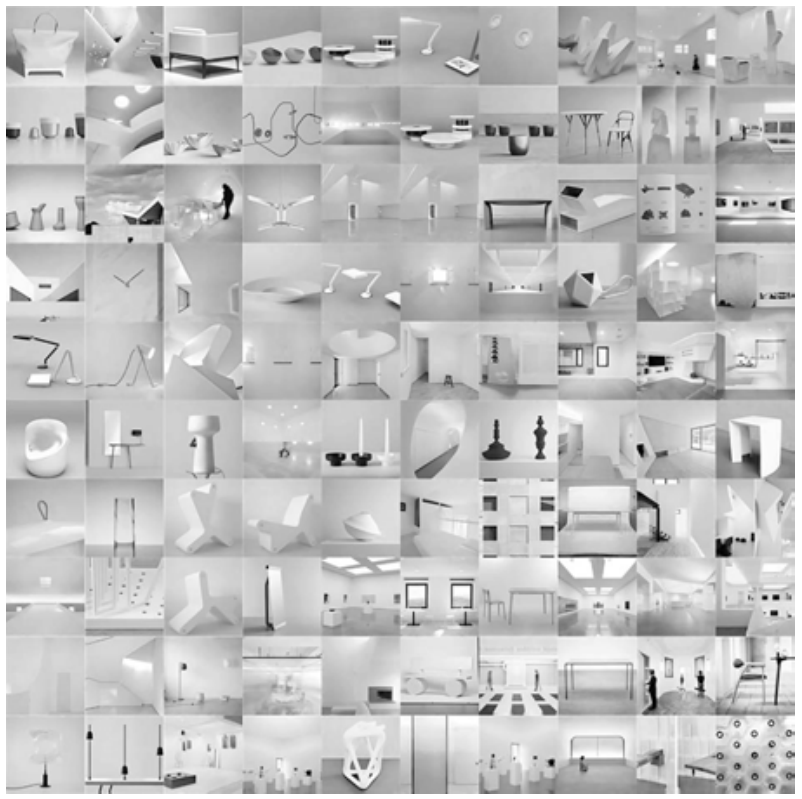


Or the patterns. Oh, I like patterns and matrices! They can become anything; they are abstract enough, but always with an odour:

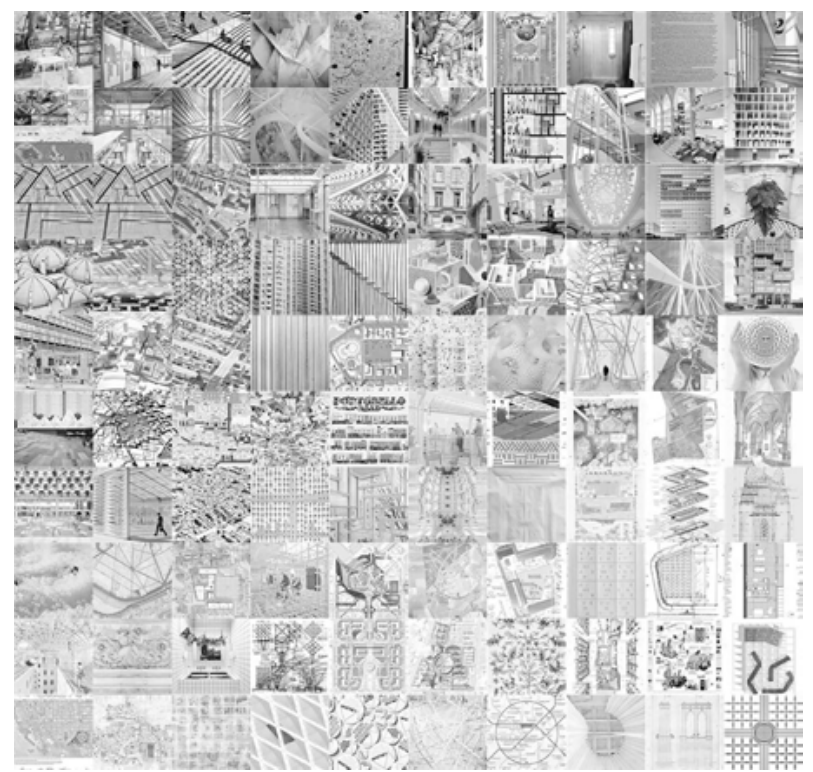

FIG 9

Flavour 4

Patterns

And the buildings, let's not forget buildings. The distilled crystals. But which ones, the vertical ones or horizontal, simple or complex, for gods or for people?

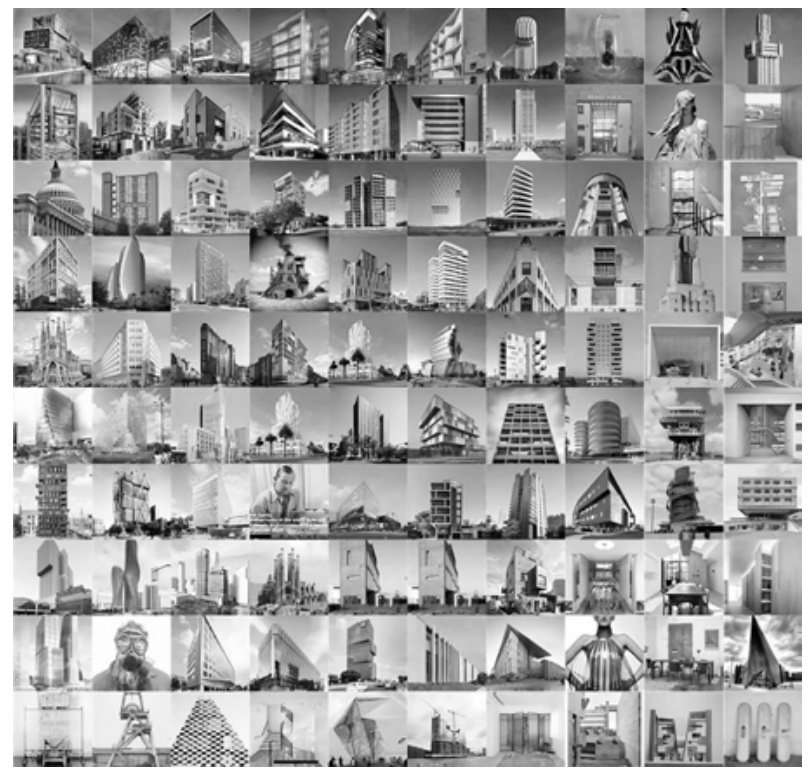

FIG IO

Flavour 5

Distilled Crystals 
Ilike a bit more the horizontal ones, inhabited by gods. That's just my taste, maybe with a bit of green garnish ... yes, a generic setup, a huge potential:

FIG II

Flavour 6

Green Garnish

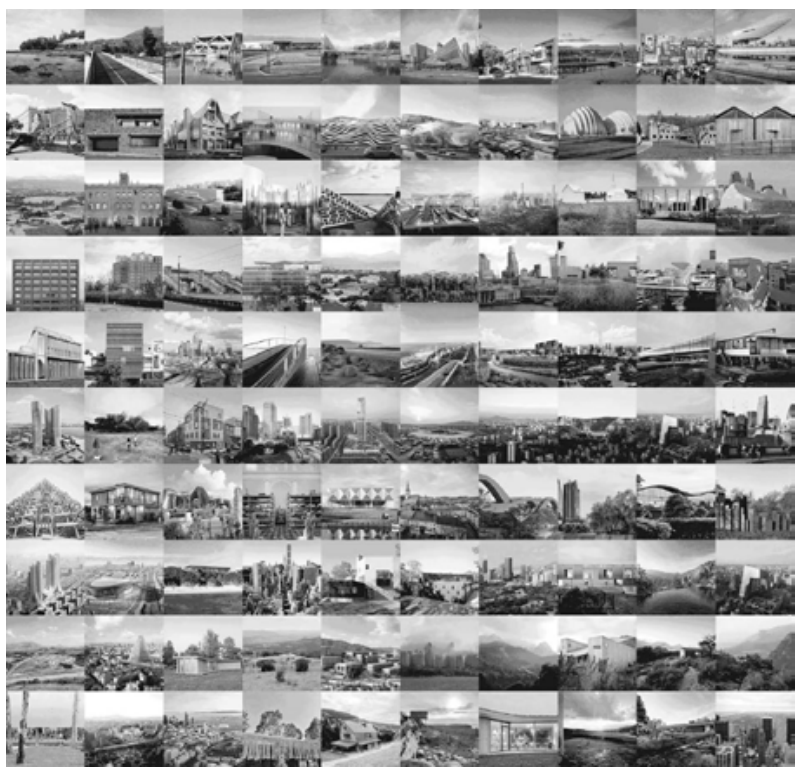

This can go on forever, from sparse smells to condensed flavours. An aftertaste is still present. I think I am onto something. That's my taste condensed and projected back onto the cloud. Each flavour is as consistent and infinite as an independent Instagram account. A spice route composed of many cells, each one containing another table full of flavours. Some known, some unknown. Yes, one is composing with unfamiliar flavours. There is no need to explicitly predefine what a flavour, object, texture, house, drawing or an image is. That is the beauty of information, a virtual full flavour. Brands and blends are dancing around the void.

\section{THAT WHICH BLOWS}

My consistency, my many brands. An environment of fluctuating interferences. Colourful objects, flavourless photographs. Trends in settings, aromas, drawings, motives, fashion ... Bazaars, data banks, markets ... Not fearing a lot. Playing, observing, collecting fast. Making artificial flavours. Blends are being distilled from a lot. Taste is a digital filter, a vector in a particular context. It changes as the context changes, but stays intimate, particular, or deliberate. It is an adventure, a game, an articulation, an explosion and a condensation of flavours. Behaving like social media and search engines. Mixing streams are encapsulating the 
world; a storm of letters and numbers; an inverse of Google, Facebook, Instagram. An ability to articulate multiple avatars. A dance around an empty axis of lifestyles at any particular moment in life. A fantastic occasion of articulating in millions.

This is the taste of my day, my flavour, my filter; a cocktail out of patterns and drawings, horizontal buildings with green garnish ... that's all. This is what I like. It is my empty centre for today. I also like other streams and objects; I can have many avatars. That's why the centre is empty-it is not explicit. I can project whatever I like. I never say why I like something, only what I like. Images are passing through. It is working: I am getting a mask. It is not perfect, but I can always tune it in another way. A taste is developing. Flavours are not directed towards an ideal blend, but towards the ever-changing conceptions of taste, constantly refining their own role. Anyway, it is my taste of the day. My projection on ArchDaily and Dezeen. A hybrid. Tomorrow is a new day, a new mask, a new identity, a new brand. I can have many of them. Every day is different. The void is never fixed. Many flavours, various masks. Brands become expressions dancing around the void. They are symbolic and algebraic; figures, fugues, faces, masks, atoms, elements, characters, avatars, indexes. It is a play with flavours on a cloudy day.

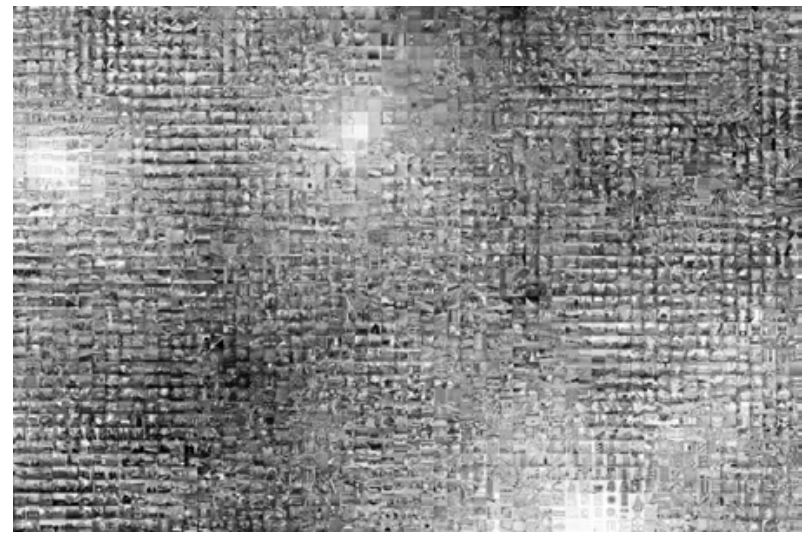

FIG I2

Blend of the Day 
